\title{
Four Simple Questions: Evaluating the Effectiveness of Half-Day Community Workshops Designed to Increase Awareness of Coastal Cetacean Conservation Issues in Sarawak, Malaysia
}

\author{
Gianna Minton, Sarawak Dolphin Project, Institute of Biodiversity and
} Environmental Conservation, Universiti Malaysia Sarawak, Sarawak, Malaysia and WWF Gabon, Libreville, Gabon

Anna Norliza Zulkifli Poh, Sarawak Dolphin Project, Institute of Biodiversity and Environmental Conservation, Universiti Malaysia Sarawak, Sarawak, Malaysia

Jenny Ngeian, Sarawak Dolphin Project, Institute of Biodiversity and Environmental Conservation, Universiti Malaysia Sarawak, Sarawak, Malaysia

Cindy Peter, Sarawak Dolphin Project, Institute of Biodiversity and Environmental Conservation, Universiti Malaysia Sarawak, Sarawak, Malaysia Andrew Alek Tuen, Institute of Biodiversity and Environmental Conservation, Universiti Malaysia Sarawak, Sarawak, Malaysia

Community workshops were held in coastal locations in Sarawak to raise awareness of cetacean conservation. Interviews were conducted up to 2 years later in four "workshop communities" as well as four villages where workshops were not conducted. Comparison of responses between respondents who had attended workshops $(n=127)$ versus those who had not $(n=233)$ indicate that workshop attendence led to significantly higher rates of "correct" responses on all three basic measures of cetacean conservation awareness. However, fishermen demonstrated a low level of knowledge of how to handle accidental entanglements, indicating a need for more effective communication strategies for this target group.

\section{INTRODUCTION}

Address correspondence to Gianna

Minton, Sarawak Dolphin Project, Institute of Biodiversity and Environmental Conservation, Universiti Malaysia Sarawak, 94300 Kota Samarahan, Sarawak, Malaysia. E-mail: Gianna. minton@gmail.com
The Kuching and Similajau areas of Sarawak's coastline are known to host populations of Irrawaddy dolphins (Orcaella brevirostris) and finless porpoises (Neophocaena phocaenoides) (Minton, Peter, \& Tuen, 2011), species which 
are considered vulnerable to extinction in the IUCN Redlist of Endangered Species (IUCN, 2008). Research has shown accidental entanglement in fishing gear (by-catch) to be the most significant anthropogenic threat to marine mammals worldwide (e.g., Read, Drinker, \& Northridge, 2006) and interview surveys conducted in Sarawak, Malaysia indicated that over 200 cetaceans are accidentally caught in fishing gear per year (Jaaman, Lah-Anyi, \& Pierce, 2009). Habitat degradation from coastal construction, waste disposal, and agricultural or industrial run-off also pose significant threats to coastal cetacean populations worldwide and in the SE Asian region (Jefferson, Hung, \& Würsig, 2009; Kannan, Ramu, Kajiwara, Sinha, \& Tanabe, 2005). While empirical research on dolphin populations is essential in conservation efforts, education and awareness raising in coastal communities is a crucial step in helping to mitigate the threats to these vulnerable and possibly endangered populations.

Researchers involved in the Sarawak Dolphin Project conducted six community workshops in coastal fishing villages bordering the project's key research areas in Kuching and Similajau. Workshop participation was extended to entire village populations, with the key target audiences comprising school children and fishermen. The main aims of the workshops were to raise awareness of cetacean conservation issues in coastal fishing communities, and to inform inhabitants of the correct procedures for, and value of, reporting accidental entaglements or strandings of coastal cetaceans in their area. Although this type of community intervention is not unusual in cetacean conservation initatives, few projects have evaluated the effectiveness of such interventions (Van Bressem, AlfaroShigueto, Geysen, Onton, \& Vega, 2006). In order to assess the workshops' impact, and to help direct future cetacean conservation community education strategies, we developed a simple, low-cost follow-up questionnaire based on four key questions. To test the hypothesis that workshops had been effective in conveying the key conservation messages that we wanted to transmit, we analyzed questionnaire results to determine whether there were significant differences in rates of correct and incorrect responses between respondents who had attended the workshops and those who had not. We hope that the results of this evaluation will allow our workshops to serve as a model for future intervention and awareness-raising strategies in the region.

\section{METHODS}

Between March 2009 and July 2010, community workshops were held in six different coastal locations in the greater Kuching and Bintulu/ Similajau regions (see Fig. 1).

These typically involved between 100 and 200 participants each, ranging from toddlers to octogenarian retired fishermen. Each workshop consisted of a 45-60 min multimedia presentation on basic cetacean biology and conservation issues, emphasizing the fact that dolphins and porpoises found close to the targeted villages are mammals that are slow to reproduce and vulnerable to a number of threats, including habitat degradation from coastal developments and accidental bycatch in fishing gear. Presentations included a lively narrative, many striking photographs and video clips and no text, tables, or charts. Following the presentation, school children participated in a coloring and drawing competition that incorporated knowlege about the dolphin species and their habitats while adult village members engaged in an open dialogue session with two or three locally based researchers.

From January to May 2011, follow-up interviews were conducted in four of the villages where workshops were held, as well as four neighboring villages in the same region where workshops had not been conducted. Questionnaires consisted of four simple questions (translated to English from the Malay language/local dialect that was used during interviews): 